\title{
Validation of a computational model of a press using 3D measurement with elimination of manufacturing inaccuracies
}

\author{
T Keckstein ${ }^{1, a}$, J Jirasko ${ }^{1, b}$ and P Votapek ${ }^{1, c}$ \\ ${ }^{1}$ Department of Machine Design, Faculty of Mechanical Engineering, University of West Bohemia in Pilsen, Univerzitni 22, 30614 Pilsen, Czech \\ Republic
}

\begin{abstract}
This paper focuses on advanced measurement methodology and its evaluation with the validation of an FEM computational model. Using the methods described in this paper, it is possible to implement values from FEM computation to places that are difficult or impossible to measure. The methods and analyses are carried out on a hydraulic press with a working force of $4000 \mathrm{kN}$ used for pressing acoustic and interior parts from fabrics. The methodologies are not only limited to hydraulic presses, but are also generally applicable to other machines.
\end{abstract}

\section{Introduction}

Great emphasis is currently placed on fulfilment of contract terms and assigned parameters in machine specification. Therefore, advanced methods of measurement and analysis are continuously being developed to make the process of verification quicker and more efficient. Measurement is not only advantageous for machine handover to customers, but it is also beneficial for machine manufacturers, who can verify the required parameters of a machine using these measurement methods and thus be more competitive and be provided with better know-how. The feedback between the measurements and FEM (Finite element method) computations is very important. This feedback provides the manufacturer with a clear overview of how much these computations can be relied on and what their deficiencies are.

The economic competitiveness of a machine is very important for press manufacturers in the market economy. Presses must meet the customers' technical requirements and the producer is forced to achieve these parameters with the lowest production costs. Requirements on product accuracy continue to rise with the development of new, innovative products. With today's advanced computational methods, producers are able to create lighter machines that are not as over-dimensioned as they used to be. This paper describes methods for verifying the accuracy parameters of presses. The field of presses is very wide and there are many press manufacturers for various forming operations. This article deals with a press from the automotive production sector.

Measurements on a real press were made. Based on the results of these measurements and the addition of values to areas where it is not possible to measure, a methodology was developed to eliminate manufacturing inaccuracies. The generalized outputs of this work are also applicable to other production machines, as a general methodology was created.

\section{Accuracy of forming machines- presses}

Production accuracy is the ability of a machine to produce accurately. Machine inaccuracy affects the resulting product deviation from a theoretically accurate model. The higher accuracy the machine has, the less technological operations are needed to finish the product. [1].

\subsection{Types of accuracy of forming machines [1]}

The title is set 17 point Times Bold, flush left, unjustified. The first letter of the title should be capitalized with the rest in lower case. It should not be indented. Leave 28 $\mathrm{mm}$ of space above the title and $10 \mathrm{~mm}$ after the title.

\subsubsection{Geometrical accuracy.}

It includes deviation of dimensions, shape and position of machine parts that determine the position and relative trajectory of working machine parts (e.g.: tool). Accuracy is determined in an unloaded state according to standards. This accuracy is influenced by the production accuracy of the individual parts of a machine and the accuracy of their assembly.

\subsubsection{Kinematic accuracy.}

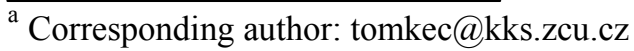


It is an expression of inaccuracies in mechanical motion joints. These errors are caused during manufacture and assembly of individual parts of a machine.

\subsubsection{Working accuracy.}

This accuracy is tested on a sample product. The shape, dimensions and mutual position of the surfaces are measured. If a manufacturer guarantees certain parameters of a machine (deflection, flatness, parallelism, etc.) under a specific load, these parameters are also measured during the machine handover to a customer.

The measured parameters of presses are defined, for example, in standards [2], [3], [4] (ISO 6899, IS 14877, JIS B6403), which also determine how these parameters are measured. Generally, these parameters are checked the flatness of the clamping plates (figure 1-A), the parallelism of the clamping plates (figure 1-B), the perpendicularity between the ram movement and the table clamping plate (figure 1-C). Furthermore, the parallelism with an eccentrically inserted member is measured, thereby determining the clearance in the guideways (figure 1-D).

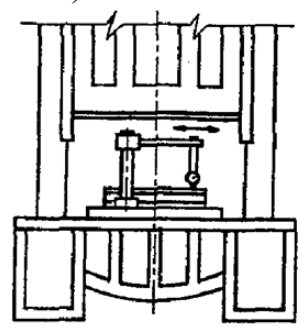

A

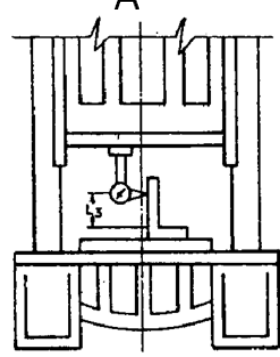

C

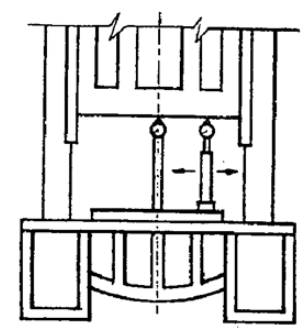

B

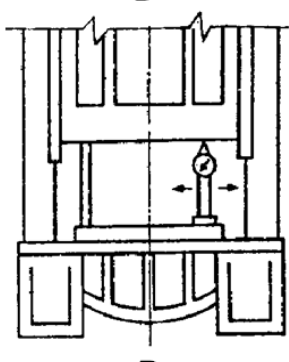

$\mathrm{D}$
Figure 1. Measuring methods of geometric parameters [3]

\section{FEM analysis of $4000 \mathrm{kN}$ hydraulic press- Static computation}

The analysis is performed on a hydraulic press used for the production of acoustic and interior parts of a car. Acoustic and interior parts are found in private cars, commercial vehicles, trucks and other types of vehicles. The parts are produced by different methods, e.g. pressing, cutting, pinching or foaming. [5,6]. Acoustic parts are designed to reduce noise and vibrations from the engine, chassis and outside environment. They also reduce thermal influences from the engine and the outside environment. Acoustic parts, unlike interior parts, are not normally seen. [5], [6].

The semi-products of the part are placed into a heated mould in a press where they get their final shape under a defined pressure, or rather by a defined compression. The main parts of the press are described in figure $2 \mathrm{a}$. The analysis was carried out using finite element method in Abaqus software. The geometric symmetry of the press and the centre load was considered, so only one quarter of the press needed to be solved.

Thermal-static computations were performed for this press, where the thermal field and the thermal influence on the frame were analysed. The papers $[7,8]$ deal with this, and the computational analysis is described in detail. This paper is focused on verifying the static computation of the press by measuring and also on a proposal of a methodology to remove manufacturing inaccuracies.

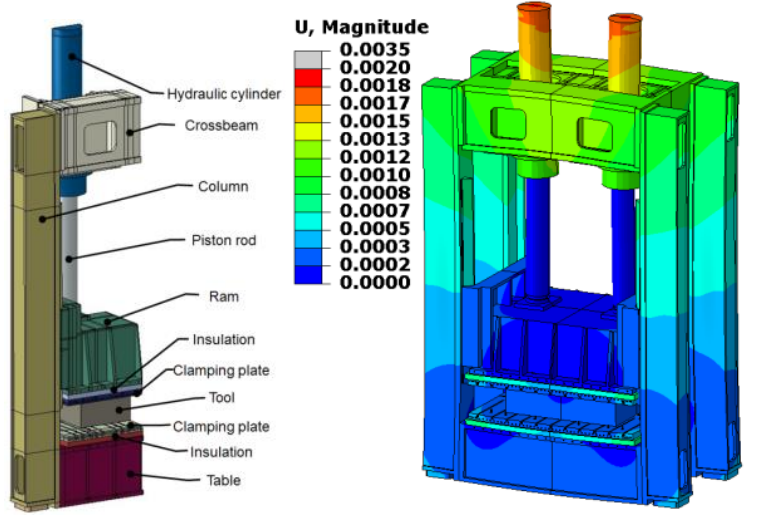

Figure 2. a) Main parts of the press, b) FEM analysis - Overall displacements on the press frame $[\mathrm{m}]$

\section{Experimental measurement of displacement of the press}

This measurement was performed to verify the results of the FEM computational model of the press. The measurement was made on a real machine (see figure $3 \mathrm{a}$ ) with a Leica Laser Tracker LTD800. Point measurement was chosen for this verification. This measurement determines the position using a measuring sphere with a reflector.

The clamping plate was marked with a raster of points for measurement purposes. Then the measuring sphere was placed at every point on the raster and its position was measured. The measurement of the clamping plates for presses is described in standards: ISO 6899, JIS B6403, IS 14877. The lower table was measured where the deformation (displacements) values are higher and the measurement results are not so burdened by the manufacturing and assembly tolerances, as it is in the case of the ram where the total displacements on the clamping plate are smaller.

The first measurement was performed on the lower clamping plate in the unloaded state without a tool. This measured the manufacturing and assembly deviations at the individual measuring points of the entire surface of the clamping plate.

For the second measurement a mould was placed into the press to measure the displacements under the pressing load. The mould was placed in the press axis so that the press was loaded centrally. The mould was closed 
symmetrically on the stops without a semi-product that would cause additional side forces. Only points that were accessible around the mould were measured, i.e. the points below the mould were not included in this measurement.

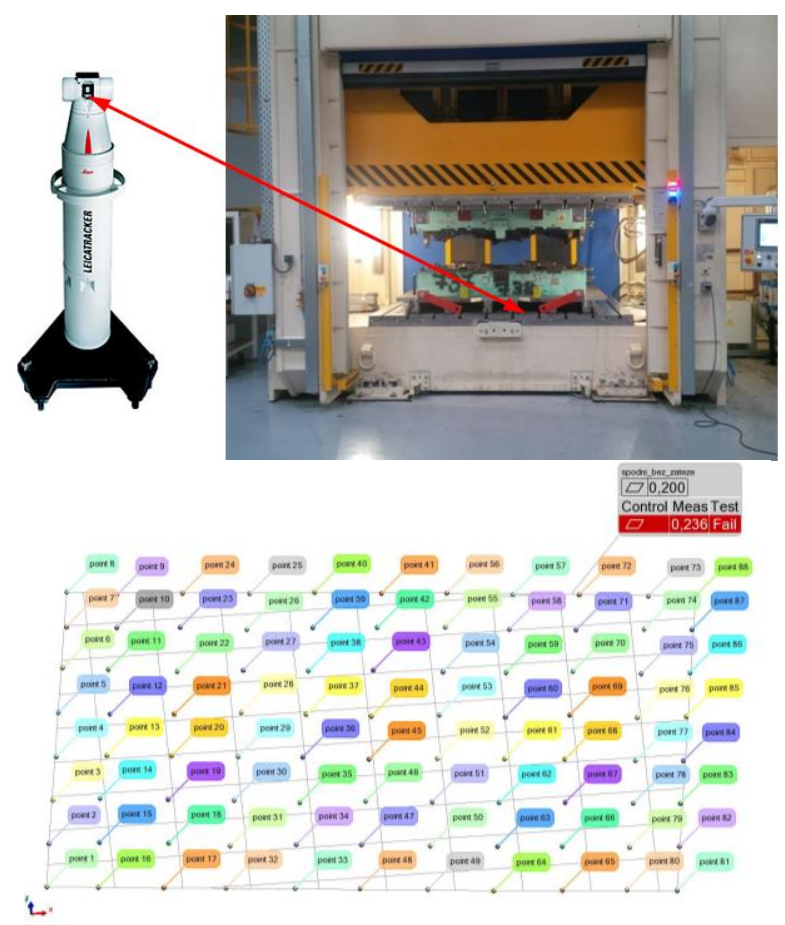

Figure 3. a) The Leica Laser Tracker LTD 800 and $4000 \mathrm{kN}$ press used for the verification of displacements [9], [10] b) Measured raster on lower clamping plate in first measurement without load

The expected manufacturing tolerances that have been validated by the measurement need to be 'filtered' to verify the displacements of the clamping plate. Therefore, a method has been proposed to eliminate these inaccuracies. The basis of this method is that the displacement of the points in the $\mathrm{z}$ axis of the second measurement is evaluated against the reference surface which was determined by the first measurement of the points. The surface was created by interpolating the measured points.

Figure $3 \mathrm{~b}$ and figure $4 \mathrm{a}$ show the output from the PolyWorks software, which gives a graphic display of the measured points and subsequent evaluation. The points from the second measurement are evaluated according to the plane interpolated through the points from the first measurement (figure 4b). The measured and calculated values of flatness and deflection on the measured strip of points are shown in Table 1 and Table 2.

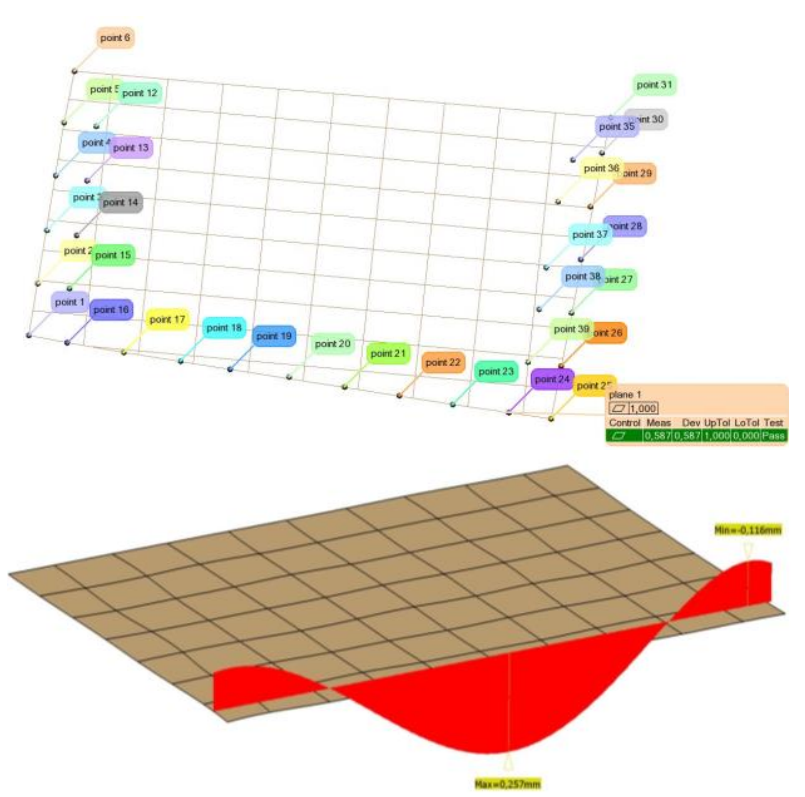

Figure 4. a) Measured point raster in second measurement with the tool and pressing force of $4000 \mathrm{kN} \mathrm{b}$ ) Evaluation of the second measurement against the reference surface

Table 1. Values of flatness

\begin{tabular}{|l|c|}
\hline & $\begin{array}{c}\text { Flatness } \\
\text { [mm] }\end{array}$ \\
\hline $\begin{array}{l}\text { Computational model for validation - } \\
\text { load } 4000 \mathrm{kN}+\text { gravity }\end{array}$ & 0.32 \\
\hline $\begin{array}{l}\text { First measurement (evaluation in } \\
\text { PolyWorks, figure 3b) - clamping plate } \\
\text { without load - production and assembly } \\
\text { inaccuracies }\end{array}$ & 0.236 \\
\hline $\begin{array}{l}\text { The second measurement (evaluation in } \\
\text { PolyWorks, figure 4b) - clamping plates } \\
\text { with load (flatness evaluated from the } \\
\text { area around the mould, manufacturing } \\
\text { and assembly inaccuracies are included } \\
\text { in the evaluation) }\end{array}$ & 0.587 \\
\hline $\begin{array}{l}\text { Evaluation of the measurement - flatness } \\
\text { evaluated using the reference surface } \\
\text { from the first measurement without } \\
\text { adding values of the displacement under } \\
\text { the tool from the FEM model }\end{array}$ & \\
\hline $\begin{array}{l}\text { Evaluation of the measurement - flatness } \\
\text { evaluated using the reference surface } \\
\text { from the first measurement with added } \\
\text { values of the displacement under the tool } \\
\text { from the FEM model }\end{array}$ & 0.37 \\
\hline
\end{tabular}

Table 2. Deflections on the measured strip of points

\begin{tabular}{|l|c|}
\hline & $\begin{array}{c}\text { Deflections on the } \\
\text { measured strip of } \\
\text { points [mm] }\end{array}$ \\
\hline $\begin{array}{l}\text { Computational model for } \\
\text { validation - load } 4000 \mathrm{kn}+ \\
\text { gravity }\end{array}$ & 0,28 \\
\hline $\begin{array}{l}\text { Value of deflection determined } \\
\text { from the reference surface }\end{array}$ & 0,37 \\
\hline
\end{tabular}




\section{Conclusions from measurement}

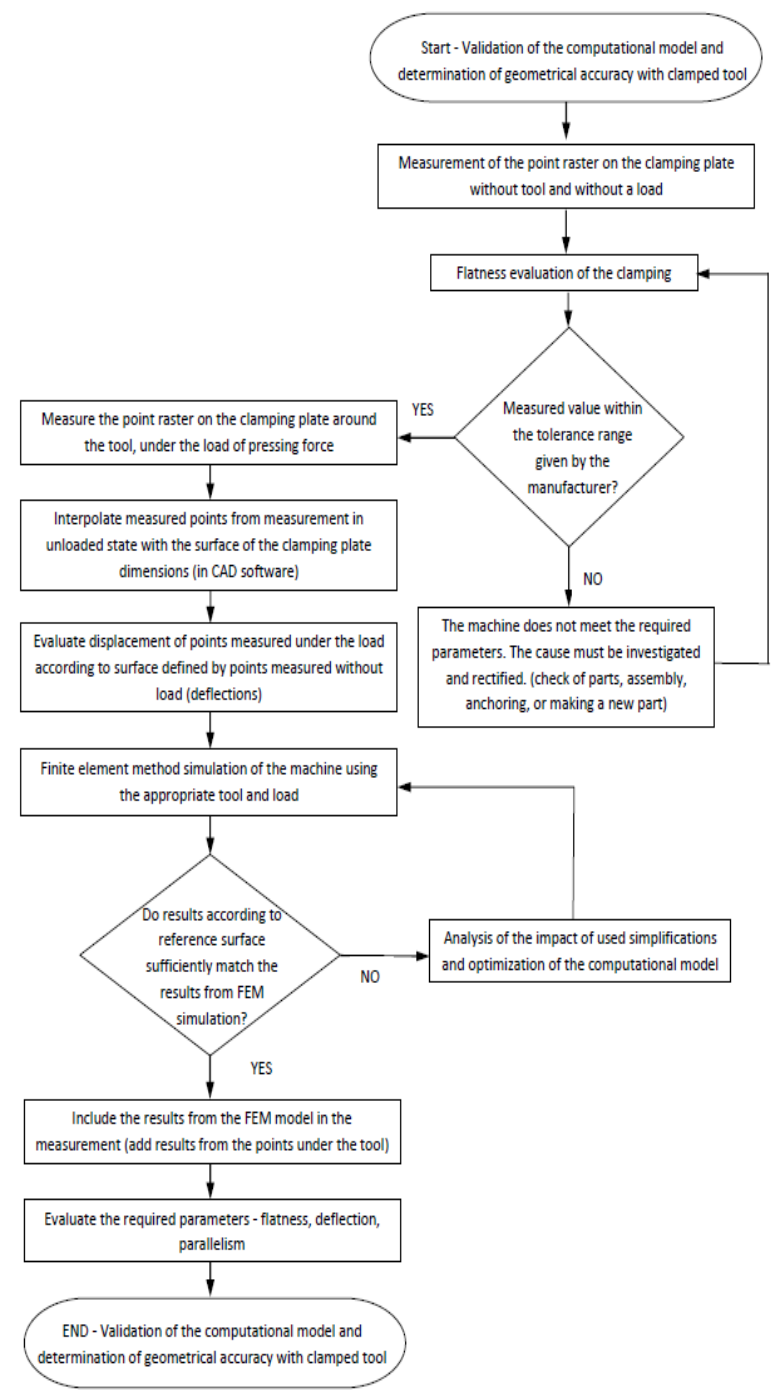

Figure 5. Flowchart

It has been confirmed that the manufacturing and assembly tolerance values have a crucial influence on the evaluation of results of the stress for this size of press. Assuming that the clamping plate is deformed under the tool equally as in the computation model, the value of flatness would be $0.05 \mathrm{~mm}$ higher, so it would be $0.42 \mathrm{~mm}$. By comparing the calculated $(0.32 \mathrm{~mm})$ and complemented values of the flatness with the calculated nodes under the mould $(0.42 \mathrm{~mm})$ and comparing the calculated $(0.28 \mathrm{~mm})$ and the measured $(0.37 \mathrm{~mm})$ values of deflection on the strip of points, it follows that the values of deflection are $30 \%$ higher than calculated. Therefore, this must be taken into account when designing the machine. The higher stiffness of the computational model is due to a simplified use of a rigid joint between the columns of the press and the lower table which is stiffer than the joint using a key and bolts. By adding more contacts and replacing the simplifications of the screw connections, a more accurate computational model can be achieved. However, this modification to the computational model results in an extension of the computational time.

\section{Proposal of methodology and meeting the standards for measuring presses}

Customers require a press to be measured with a clamped and loaded tool. The parameters usually evaluated are: flatness, parallelism and displacement (deformation) caused by the load. The measurement described in this paper, or its methodology and evaluation, are not currently covered in the standards. The proposed methodology is based on these standards and reduce their 'deficiencies' - elimination of manufacturing inaccuracies from measurements for analysis of deflection, adding the measurement of computed values in the inaccessible area under the tool. The methodology allows a comprehensive evaluation of the accuracy and deformation of the entire surface of the clamping plate when measured with the conventional tool clamped. The proposal of these modifications respects the requirements of customers, the possibilities of the computations, and the measurement methods currently used. The methodology for determining the geometric accuracy of the clamping plate of the press with a loaded tool is described in the flowchart, see figure 5. See figure 6 for a simplified graphical depiction of the methodology.

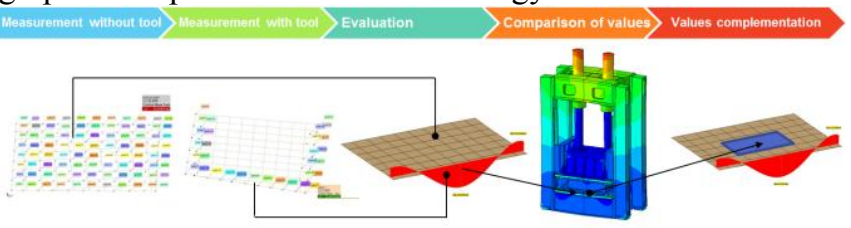

Figure 6. Graphical depiction of methodology

\section{Conclusion}

This methodology has been developed to filter out manufacturing inaccuracies from measurements to verify deformations from load and to complete measured values with computed values in areas inaccessible for measurement. This methodology is generally applicable to other types of machines or similar applications. The methodology can be used not only for machine handover, but also for the machine manufacturer, who can verify the proposed parameters of the machine via the measurement, and thus enables it to be more competitive with sustainable know-how. The feedback between the measurements and the FEM simulations is very important, as it gives the manufacturer a clear overview of how much they can rely on these computations and what the deficiencies are.

In the future, 3D measurement and validation of results will become increasingly important, and these measurements will be used much more often. For this reason, attention needs to be paid to this topic and these methods need to be further developed.

\section{References}

1. Čechura, M, Hlaváč, J a Staněk, J. Konstrukce tvářecích strojů. Plzeň: ZČU, 2014. ISBN 978-80261-0513-8. 
2. ČSN ISO 6899. Přejímací podmínky mechanických lisů s vyložením. Zkoušky přesnosti. Praha: Český normalizační institut, 1992.

3. S 14877-1 (2000). Hydraulic Presses - Straight Sided Column/C-Frame Type, Part 1: Test Chart for Geometrical Accuracy. New Delhi: Bureau of Indian Standards, 2000.

4. JIS B6403-1994. Hydraulic presses - Testing of the accuracy. Tokyo: Japanese Standards Association, 1994.

5. Hynek, M., Max, A., Grach, M., Muller E. KA 03 Pohledové díly - Pohledové díly. Plzeň: Západočeská univerzita v Plzni, 2012.

6. Hynek, M., Max, A., Grach, M., Muler, E. KA 02 Akustické díly - Akustické díly. Plzeň: Západočeská univerzita v Plzni, 2012.

7. Jirásko, J., Max, A., Kotntner, R. A coupled temperature-displacement numerical analysis of hydraulic press workspace. In Proceedings of the
ASME 2016 International Mechanical Engineering Congress and Exposition (IMECE 2016). New York, NY 10016 - 5990: ASME, 2016. s. V04BT05A043. ISBN: 978-0-7918-5063-3.

8. Jirásko, J., Max, A. The effect of cooling circuits in a press frame on the resulting accuracy. In DEStech Transactions on Materials Science and Engineering. 439 DUKE STREET, LANCASTER, PA 176024967: DEStech Publication, Inc., 2018., ISSN: 2572889X.

9. Leica Industrial Measurement Systems Launches Next Generation LTD800 Laser Tracker. Metrologyworld.com [online]. 2018 [cit. 2018-06-01]. Available https://www.metrologyworld.com/doc/leicaindustrial-measurement-systems-launches-0001

10. Catalogs and documentation for measuring system Leica Laser Tracker LTD800. B.m.: Leica Geosystems AG, 2006. 